\title{
Cyclooxygenase 2 Modulates Killing of Cytotoxic T Lymphocytes by Colon Cancer Cells
}

\author{
Quanxin Wang', Yoshiyuki Takei ${ }^{2}$, Osamu Kobayashi ${ }^{1}$, Taro Osada ${ }^{1}$, and Sumio Watanabei,* \\ ${ }^{1}$ Department of Gastroenterology, Juntendo University School of Medicine, 2-1-1 Hongo, Bunkyo-ku, \\ Tokyo 113-8421, Japan \\ ${ }^{2}$ Department of Gastroenterology and Hepatology, Division of Clinical Medicine and Biomedical Science, Institute \\ of Medical Sciences, Mie University Graduate School of Medicine, 2-174, Edobashi, Tsu, Mie 514-8507, Japan
}

Received 10 February, 2009; Accepted 22 February, 2009

\begin{abstract}
Summary Although anti-cancer effects of cyclooxygenase 2 (COX2) inhibitors have been reported, most studies focused on the direct effects of COX2 inhibiters on colon cancer cells. On the other hand, several types of cancers express Fas ligand (FasL) and/or TRAIL and mediate apoptosis of $T$ cells in vitro. The "counter-attack" machinery may account for the mechanisms by which tumors evade host immune surveillance. In this study we determined if COX2 inhibitor could modulate effector molecules of cell death on colon cancer cells changing their effects on cytotoxic T lymphocytes. Colon adenocarcinoma cells, HCA7 and HCT116, the former COX2-positive and the latter COX2-negative, were pre-incubated with/without a COX2 inhibitor, NS398. Subsequently, the cells were co-cultured with Jurkat $T$ cell leukemia cells and damage to Jurkat cells was determined. Treatment with NS398 resulted in reduction of expression of FasL and TRAIL in HCA7 cells, whereas NS398 did not affect the expression of FasL and TRAIL in HCT116 cells. The number of viable Jurkat cells was diminished when cells were co-cultured with naive, non-pretreated HCA7 or HCA116 cells. Preincubation of HCA7 cells with NS398 before co-culture blunted the HCA7 cell-induced cell toxicity on Jurkat cells. In contrast, pretreatment with NS398 failed to inhibit the HCT116-induced Jurkat cell killing. Our results suggest that COX2 regulates the expression of FasL and TRAIL on COX2-positive colon cancer cells thereby evoking a counter-attack against cytotoxic $T$ cells, which may lead to compromised host immune responses.
\end{abstract}

Key Words: cyclooxygenase 2, FasL, TRAIL, colon cancer cells, cytotoxic T lymphocytes

\section{Introduction}

Cyclooxygenase (COX), a key enzyme required for the synthesis of prostaglandins, exists in two different isoforms, COX1 and COX2. Although COX2 is not detectable in most tissues, it is known that its expression is regulated by mitogenic stimuli and tumor promoters [1-4]. COX2 is overexpressed in about $40 \%$ of adenomatous polyps and

\footnotetext{
*To whom correspondence should be addressed.

Tel: +81338133111 Fax: +81338138862

E-mail:sumio@juntendo.ac.jp
}

$85 \%$ of colorectal cancer [5]. The ratio of COX2 positive polyps increased in a size-dependent manner [6]. Moreover COX2 overexpression in colon cancer was associated with tumor size, stage and the status for lymph node metastasis [7].

Several studies have shown that inhibitors for COX2 reduce the incidence and development of colorectal cancer. Celecoxib, a COX2 selective inhibitor, reduced colon polyps in familial adenomatous polyposis (FAP) patients in a 6-month, randomized, controlled clinical trial $[8,9]$. Further, numerous experiment in animal studies demonstrated a significant efficacy of selective COX2 inhibitors for the prevention of colorectal tumors [10-14]. The precise 
mechanisms by which a selective COX2 inhibitor prevents growth of polyps or the progression of existing polyps are not fully understood. Nevertheless, there are some reports suggesting that several anti-tumor mechanisms are involved, including the ability to induce apoptosis in colon cancer cells [15], the capacity to inhibit angiogenesis and the possibility to prevent migration and/or invasion of colon cancer cells [16-19].

It is often observed that tumors are infiltrated with lymphocytes. The tumor infiltrating lymphocytes (TILs) have been reported to correlate with prognosis of cancerbearing patients [20]. Moreover, the presence of TILs appears to be associated with less aggressive behavior of malignat neoplasms [21]. This might suggest that tumor cells are vulnerable to attack by immune effector cells such as lymphokine-activated killer cells, cytotoxic $\mathrm{T}$ lymphocytes (CTLs) and macrophages [21, 22]. However, the function of tumor-infiltrating lymphocytes, circulating $\mathrm{T}$ cell was suggested to be impaired [23, 24].

Immuno-suppression occurs in tissues where $\mathrm{PGE}_{2}$ is high. Moreover, it has been demonstrated that the impaired functions of immune cells were restored with treatment with COX2 selective inhibitors [25]. These studies suggest a possibility that $\mathrm{PGE}_{2}$ itself or induction of $\mathrm{COX} 2$ protein could suppress lymphocyte proliferation and/or cytotoxicity [26-28].

On the other hand, cancer cells occasionally express Fas ligand (FasL) or TRAIL to "counterattack" infiltrating cytotoxic $\mathrm{T}$ and/or natural killer cells. Several types of human cancers express FasL and/or TRAIL and mediate apoptosis of T cells in vitro [29-32].

These observations collectively led us to hypothesize that induction of COX2 protein in colonic tumors could modulate functions and viability of tumor-infiltrating CTLs. In this study we report that $\mathrm{COX} 2$ potentiates killing functions of the COX2-positive colonic cancer cells and this event is mediated by two apoptosis-related molecular systems, FasL/Fas and TRAIL/DR4.

\section{Materials and Methods}

\section{Cell culture and treatments}

A human colonic adenocarcinoma cell line HCT116, the Jurkat human T cell leukemia cell line and U937 human macrophage cell line were obtained from American Type Culture Collection (Rockville, MD). HCA7, another human colonic adenocarcinoma cells were a generous gift from Dr. Raymond N Dubios (Vanderbilt University Department of Gastroenterology). HCT116 and HCA7 cells were grown in Dulbecco's modified Eagle medium (DMEM) supplemented with $10 \%$ heat-inactivated fetal bovine serum (FCS), $100 \mathrm{U} / \mathrm{ml}$ ampicillin and $100 \mathrm{mg} / \mathrm{ml}$ streptomycine (Life Technologies, Rockville, MD). Jurkat and U937 cells were grown in RPMI 1640 medium with same concentrations of FCS and antibiotics. Cells were cultured at $37^{\circ} \mathrm{C}$ in the atmosphere of $95 \%$ air $/ 5 \% \mathrm{CO}_{2}$.

\section{WST assay}

HCA7 cells were suspended with DMEM culture medium at the concentration of 50,000 cells $/ \mathrm{ml} .100 \mu \mathrm{l}$ of the cell suspension was inoculated onto the each well of a 96-well plate then pre-incubated at $37^{\circ} \mathrm{C}$ for $24 \mathrm{~h}$. Various concentrations of $\operatorname{NS} 398(0,1,10,100 \mu \mathrm{M})$ were added to each well. Moreover those cells were incubated $48 \mathrm{~h}$. $10 \mu \mathrm{l}$ of Cell Counting Kit-8 solutions (Kumamoto, Japan) were administrated to the each well, and incubated for $1 \mathrm{~h}$. Cell viability in each well was determined by measuring the absorbance of $450 \mathrm{~nm}$ wave length.

\section{Co-culture of colon cancer cells and Jurkat cells}

HCA7 and HCT116 cells were inoculated onto 96 well culture plate at $1.8 \times 10^{4}$ and $1 \times 10^{4} /$ well, respectively. The cell lines were grown in DMEM containing FCS plus antibiotics. Fifty-two hours after the inoculation, both cell lines became sub-confluent, and were washed with PBS twice. Subsequently, cells were incubated with a selective COX2 inhibitor NS398 (1 or $10 \mu \mathrm{M})$ (Sigma, St Louis, $\mathrm{MO}$ ), or with an anti-FasL neutralizing antibody (Santa Cruz, CA) (83.3 nM), an anti-TRAIL neutralizing antibody (Santa Cruz) $(83.3 \mathrm{nM})$, or both for another $18 \mathrm{~h}$.

Jurkat cells were inoculated onto the well $(3 \mathrm{~cm}$ in diameter) at $8 \times 10^{5} /$ well followed by culture for $30 \mathrm{~h}$. Then, ${ }^{3} \mathrm{H}$-methyl-thymidine ( ${ }^{3} \mathrm{HMT}, 5 \mathrm{mCi} / \mathrm{ml}$ ) was added to the culture media and incubation continued for additional $18 \mathrm{~h}$. The ${ }^{3}$ HMT-labeled Jurkat cells were detached from the plate by tripsinization, washed three times with RPMI 1640 containing 5\% fetal calf serum. The ${ }^{3}$ HMT-labeled Jurkat cells thus prepared were used for co-culture for $18 \mathrm{~h}$ with either HCA7 or HCT116 colon cancer cells $\left(2 \times 10^{4}\right.$ cells/ well) that had been treated with NS398, anti-FasL and/or anti-TRAIL antibodies. The ratio of the effector (HCA7 or HCT116) cells to the target (Jurkat) cells (T/E ratio) was 10.

\section{Cell cytotoxicity assay}

Following co-culture of ${ }^{3} \mathrm{HMT}$-labeled Jurkat and colon cancer cells for $18 \mathrm{~h}$, Jurkat cells were harvested by trapping onto a grass fiber membrane. The radioactivity remaining in Jurkat cells was measured by a scintillation counter.

\section{Protein extraction}

HCA7, HCT116, Jurkat or U937 cells were incubated in the presence or absence of NS398 $(10 \mu \mathrm{M})$ for $18 \mathrm{~h}$. Subsequently, whole cells were collected, suspended in the lysis buffer $(150 \mathrm{mM} \mathrm{NaCl}, 1 \%$ Triton X-100, $0.5 \% \mathrm{Na}$ deoxycholate, $0.1 \%$ SDS with protease inhibitors) and vortexed for $5 \mathrm{~min}$ on ice. After $30 \mathrm{~min}$ of incubation, the 
suspensions were centrifuged at $15,000 \mathrm{rpm}$ for $15 \mathrm{~min}$. The cell lysates were stored at $-80^{\circ} \mathrm{C}$ until used.

\section{Western blotting}

The total concentration of cytoplasmic proteins was determined by the Bradford assay (Bio-Rad Laboratories, Hercules, CA). Thirty $\mu \mathrm{g}$ of cytoplasmic protein from each sample was diluted in SDS-PAGE loading buffer, boiled for $5 \mathrm{~min}$ and loaded onto $10 \%$ or $12 \%$ SDS-PAGE gel. The proteins were transferred to the Hybond-P positively charged nylon membrane (Amersham Life Science, Arlington Heights, IL) using a Hofer semiphor (Pharmacia Biotech Piscataway, NJ) semi-dry blotting device. After non-specific binding was blocked with $3 \%$ Blotto (3\% dry milk, $150 \mathrm{mM}$ $\mathrm{NaCl}, 20 \mathrm{mM}$ Tris-HCl $\mathrm{pH} 7.5$, and $0.05 \%$ Triton X100) overnight at room temperature, the membranes were incubated with primary antibodies against COX2, FasL, TRAIL, DR4 or Fas (Santa Cruz CA) at the concentration of 1:200. Excess primary antibodies were washed and removed, and then membranes were incubated with a horseradish peroxidase-conjugated secondary $\operatorname{IgG}$ antibody at a dilution of $1: 2,000$ in $3 \%$ Blotto solution for $1 \mathrm{~h}$. Subsequently, the membranes were washed 3 times each with TBST $(150 \mathrm{mM}$ $\mathrm{NaCl}, 20 \mathrm{mM}$ Tris-HCl pH 7.5, 0.05\% Triton X100). The membranes were then developed for 2 min with ECL regents (Amersham Life Science).

\section{Immunofluorescence analysis}

HCA7 and HCT116 cells were plated on $15 \mathrm{~mm}$ dishes and grown for $48 \mathrm{~h}$. Cells were fixed with $1 \%$ paraformaldehyde for $10 \mathrm{~min}$, and incubated $1 \mathrm{~h}$ with primary antibodies aganist FasL or TRAIL, diluted 1:500, in the presence of $10 \%$ normal goat serum. followed by addition of an FITClabeled secondary antibody (Santa Cruz). Each experiment was performed with three replicated dishes. Images were observed under a Leitz microscopy equipped with a fluorescence lamp and appropriate filters, and photographed at a magnification of $\times 400$.

\section{Results}

\section{Expression of $\mathrm{COX} 2$ in various colon cancer cell lines}

First, we determined if COX2 was expressed in HCA7 and HCT116 colon cancer cells using Western blot analysis. As shown in the Fig. 1, HCA7 cells expressed COX2 protein intensely whereas HCT116 cells express COX2 protein very faintly.

\section{Effect of NS398 on viability of HCA7 cells}

When HCA7 cells were incubated for $48 \mathrm{~h}$ with NS398, there was no significant decrease in cell viability at concentrations up to $10 \mu \mathrm{M}$. However, viability declined significantly by $10 \%$ at $100 \mu \mathrm{M}$ (Fig. 2). Therefore, we used

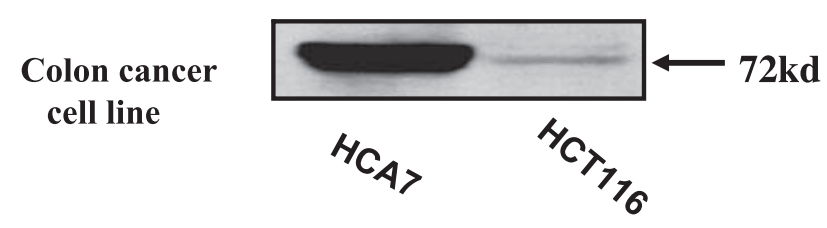

Fig. 1. Detection of COX-2 protein in human colonic adenocarcinoma cell lines. Colonic adenocarcinoma cells (HCA7and HCT116) were cultured in DMEM supplemented with $10 \%$ FCS. When cells became subconfluent, cells were lysed as described in Materials and Methods. COX2 protein was detected in the cell lysates with Western blotting. Representative photograph of bands showing COX2 protein $(72 \mathrm{kD})$.

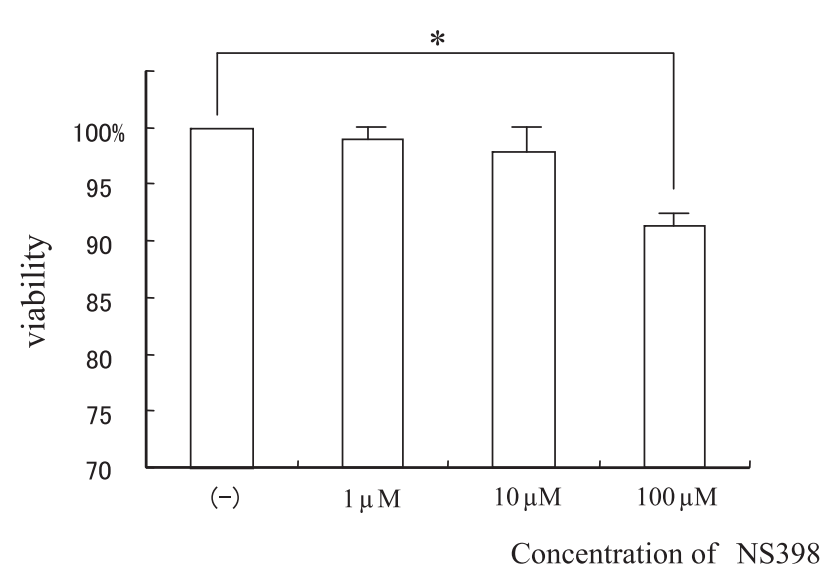

Fig. 2. Effect of increasing concentrations of a COX2 selective inhibitor NS398 on viability of HCA7 cells. HCA7 cells were cultured for $48 \mathrm{~h}$ in the presence of $0-100 \mu \mathrm{M}$ NS398. Subsequently, cell viability was determined using WST method. ${ }^{*} p<0.005$ vs $0 \mu \mathrm{M}$.

the NS398 concentrations of 1 and $10 \mu \mathrm{M}$ for the following experiments.

Expression of proteins of the FasL and TRAIL systems on colon cancer cell lines, Jurkat and U937 cells

We next evaluated the expression of FasL and TRAIL in two colon cancer cell lines, HCA7 and HCT116, the former being COX2 positive and the latter negative. Western blotting indicates that FASL and TRAIL were expressed constitutively in both colon cancer cell lines as shown in Fig. 3. To further assess the localization of those proteins in the cells, HCA7 and HCT116 were immunostained for FasL or TRAIL and viewed under a fluorescence microscopy. Both FasL and TRAIL were detected predominatly as intense green florescence spots in the intracellular compartment with some faint fluorescence along the cell membrane (Fig. 4).

Treatment with NS398, a selective inhibitor for COX2, resulted in a marked reduction of expression of FasL and 


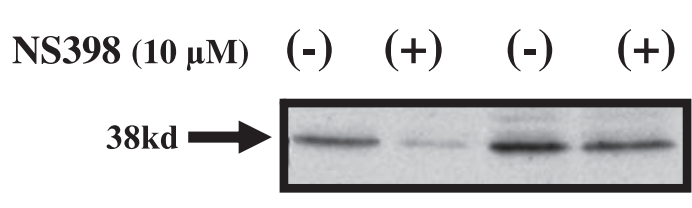

HCA7 HCT116

1st antibody FAS L

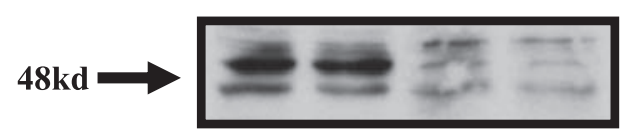

Jurkat U937

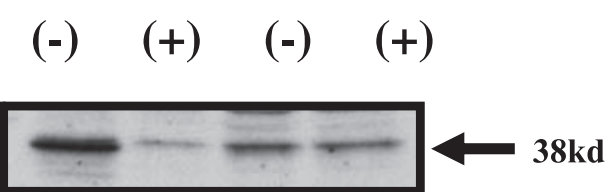

HCA7 HCT116

1st antibody TRAIL

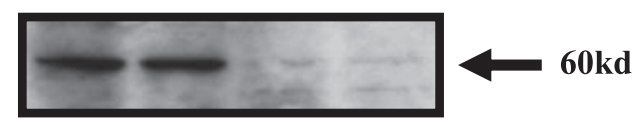

Jurkat

U937

\section{1st antibody FAS}

\section{1st antibody DR4}

Fig. 3. Expression of proteins of the FasL and TRAIL systems on colon cancer cell lines, Jurkat and U937 cells. Upper panel: HCA7 and HCT116 (upper panel), and Jurkat and U937 cells (lower panel) were cultured in the absent or presence of NS398 (10 $\mu \mathrm{M}$ ). After an $18 \mathrm{~h}$ of incubation, whole cell lysate was extracted and the expression of apoptosis related proteins (FASL and TRAIL in HCA7 and HCT116 cells; Fas and DR4 in Jurkat and U937 cells) was examined by Western blotting. Representative photograph of bands showing FasL (38 kD), TRIAL (38 kD), Fas (48 kD) and DR4 (60 kD).

HCA7
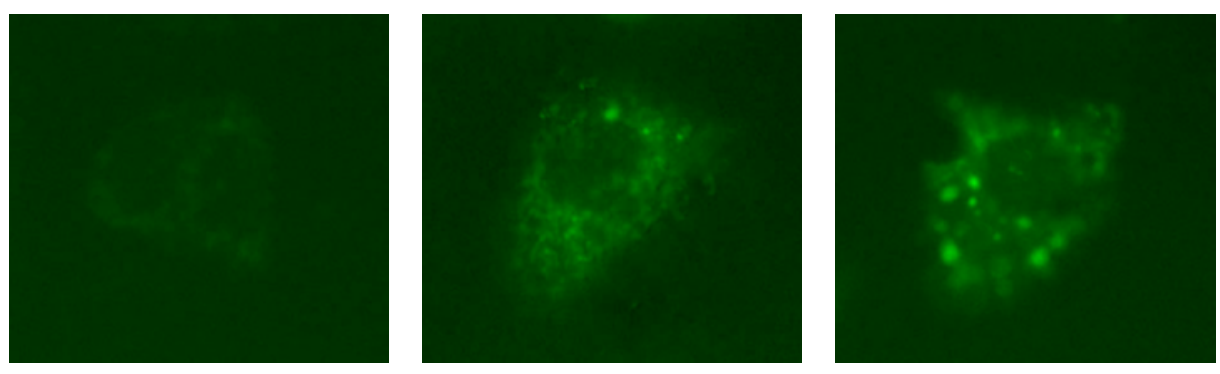

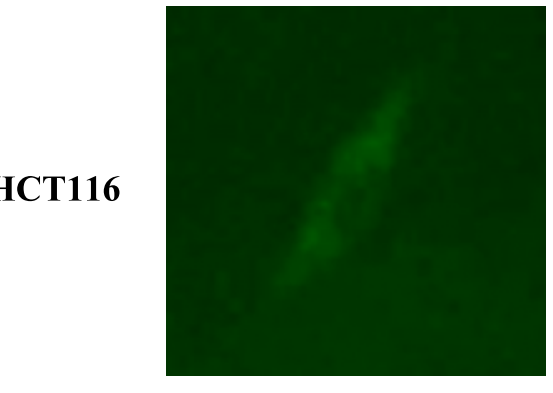

CONTROL

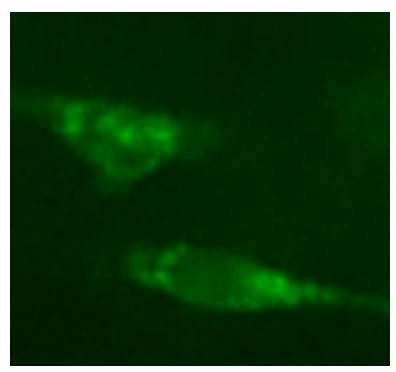

FASL

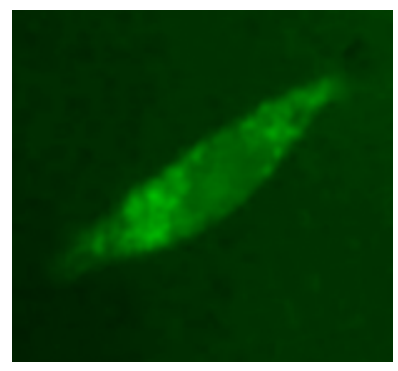

TRAIL

Fig. 4. Immunostaining analysis for FasL and TRAIL expression in HCA7 and HCT116 cells. After a 48 h of culture, HCA7 and HCT116 cells were fixed with paraformaldehyde and processed for immunostaining using a first antibody for TRAIL or FASL followed by visualization with an FITC-labeled secondary goat anti-rabbit antibody as described in Materials and Methods. Magnification $(\times 400)$

TRAIL in HCA7 cells. In contrast, NS398 did not affect the expression of FasL and TRAIL in HCT116 cells (Fig. 3, upper panel).
On the other hand, Jurkat cells, a CTL lineage, expressed both Fas and DR4. However, U937, a cell line derived from macrophage, expressed neither Fas nor DR4 (Fig. 3, lower 
(a)

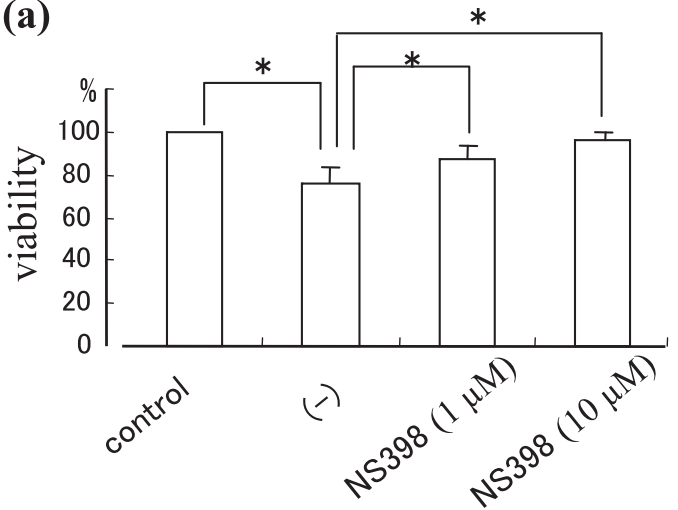

(b)

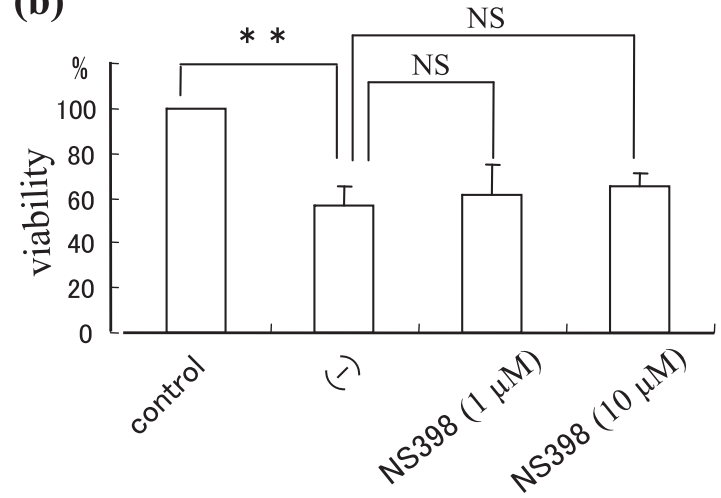

Fig. 5. Effects of NS398 on the cytotoxic ability of HCA7 and HCT116 cells against Jurkat cells. HCA7 and HCT116 cells pretreated with $\operatorname{NS} 398(0,1$, or $10 \mu \mathrm{M})$ for $18 \mathrm{~h}$ and used for co-culture with ${ }^{3} \mathrm{H}$ thymidine labeled Jurkat cells for $18 \mathrm{~h}$. Subsequently, cells were collected and radioactivity was counted by a scintillation counter. As a control, Jurkat cells were cultured for $18 \mathrm{~h}$ without colon cancer cells. ${ }^{*} p<0.001,{ }^{* *} p<0.05$ vs appropriate control. NS; not significant.

panel). NS398 failed to alter the expression of these proteins in both cells.

Effects of NS398 on the cytotoxic ability of HCA7 and HCT116 cells against Jurkat cells

The CTL system constitutes a major part of the tumoricidal machinery of immunity. Therefore inhibition of CTL functions or their survival should favor genesis and growth of tumor cells. Given this, the cytotoxic ability of colon cancer cells against Jurkat cells was evaluated in a co-culture system of colon cancer cells (HCA7 or HCT116) and Jurkat cells. The results were displayed in Fig. 5. The number of viable Jurkat cells was diminished by about $25 \%$ when cells were co-cultured $(\mathrm{T} / \mathrm{E}$ ratio $=10)$ with naive, non-pretreated HCA7 cells that were COX2-positive (Fig. 5, left). Under the same conditions, preincubation of HCA7 cells with $\mathrm{NS} 398$ at 1.0 or $10 \mu \mathrm{M}$ before co-culture blunted the HCA7 cell-induced cell toxicity on Jurkat cells in a dose-dependent manner reaching a almost complete loss of cytotoxicity at $10 \mu \mathrm{M}$.

Co-culture of Jurkat cells with a COX2-negative colon cancer cells gave distinct results. As illustrated in Fig. 5 right, co-culture with naïve HCT116 cells resulted in a decrease of viability of Jurkat cells by $40 \%$. However, pretreatment with NS398 $(1.0$ or $10 \mu \mathrm{M})$ failed to inhibit the HCT116-induced Jurkat cell cytotoxicity.

To determine if the Jurkat cell killing by HCA7 was mediated by FasL or TRAIL, HCA7 cells were incubated with either a neutralizing antibody for FasL, or TRAIL, or with both before co-culture with Jurkat cells. As depicted in Fig. 6, either anti-FasL or anti-TRAIL antibody alone could suppress the killing of Jurkat cells. Pretreatment of HCA7 cells with both antibodies resulted in a complete inhibition of Jurkat cell killing (Fig. 6).

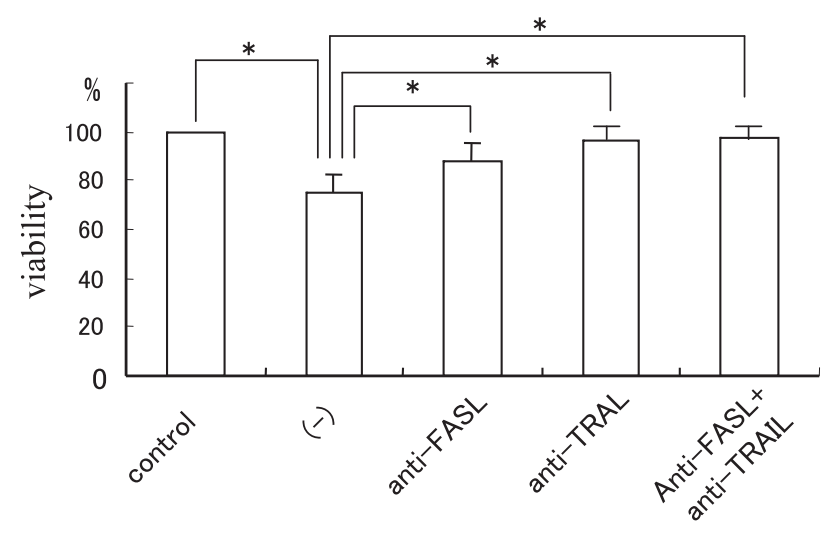

Fig. 6. Effects of nerutralizing antibodies for FASL or/and TRAIL on the cytotoxic ability of HCA7 and HCT116 cells against Jurkat cells. Conditions as in Fig. 5. HCA7 and HCT116 cells pretreated with either anti-FasL or anti-TRAIL antibody, or with both (anit-Fas + antiTRAIL) for $18 \mathrm{~h}$. After co-culture with Jurkat cells, cytotoxicity of Jurkat cells was assayed as described in Fig. 5. ${ }^{*} p<0.001$ vs control.

\section{Discussion}

The results of our study showed that killing of Jurkat cells occurs when co-cultured with colon cancer cells, HCA7 and HCT116. This observation agrees with previous reports that colon cancer cells exploit a machinery to evade immunosurveillance through counterattacking tumoricidal CTLs $[29,33]$. NS398, a selective COX2 inhibitor, attenuated the HCA7-mediated Jurkat cell cytotoxicity. This events appears likely to be mediated by two molecular systems for cell death, FasL/Fas and TRAIL/DR4. The view is supported by the following lines on evidence. First, pretreatment with NS398 reduced expression of FasL and TRAIL 


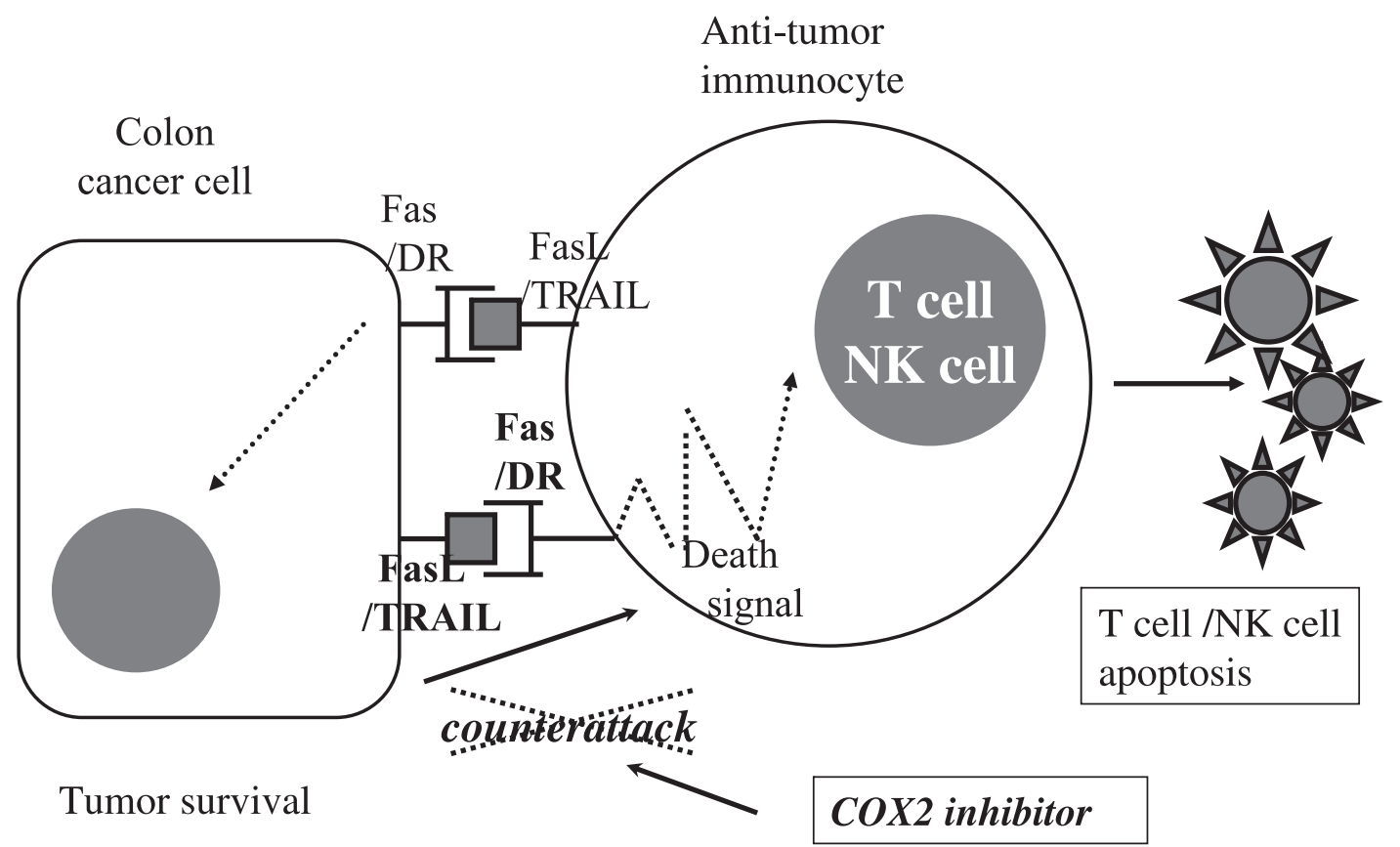

Fig. 7. Working hypothesis. For details, refer to the text.

on HCA7 cells. Secondly, HCA7-mediated cell killing was diminished by pretreatment with anti-FasL or anti-TRAIL neutralizing antibody. It is thus postulated that both of FasL and TRAIL contribute to the cytotoxicity (Fig. 6).

Although the anti-cancer efficacy of COX2 selective inhibitors has been reported, most of studies have focused on the direct effects on tumorigenicity and/or malignant potentials of colon cancer cells $[15-17,34,35]$. Our results indicate that $\mathrm{COX} 2$ regulates the expression of FasL and TRAIL on COX2-positive colon cancer cells thereby evoking a counter-attack against CTLs leading to compromised host immune responses (Fig. 7). This adds to a new insight into the role of COX2 in the progression of colon cancer cells given that numerous numbers of immune cells are infiltrated in and adjacent to colon tumors [20], an event constituting a defense mechanism against tumors through damaging tumor cells. As COX2 is expressed at an early stage of colon neoplasm [7], the effects of COX2 inhibitors on preventing the counterattack potentials of tumor cells through reduction of FasL and TRAIL may explain, at least in part, a mechanism for the chemopreventive effects of COX2 selective inhibitors.

Several points were left to be elucidated in the future studies. Among them, it is not clear yet how FasL and/or TRAIL upregulation in colon cancer cells evokes induction of apoptosis in CTLs. Beside a notion that membraneharboring death molecules exert their effects through engaging directly with respective receptors on CTLs, there is a possibility that tumor cells secret FasL and/or TRAILbearing microvesicles thereby inducing CTL apoptosis [36].
The latter mechanism appears intriguing and likely to play a major role in the HCA7-induced Jurkat cell apoptosis given that FasL and TRAIL proteins were predominatly localized in the intracellular vesicular compartments though only a faint expression of these proteins was observed in HCA7 and HCT116 cells (Fig. 4). Furthermore, the precise machinery by which COX2 regulates expression of FasL and TRAIL is also obscure.

In conclusion, the effect of COX2 selective inhibition to attenuate the counterattack of cancer cells against immune effector cells is a possible molecular mechanism through which COX2 inhibitors prevent the growth of adenomatous polyps or progression of colon cancers.

\section{Abbreviations}

COX2, cyclooxygenase 2; TIL, tumor infiltrating lymphocyte; CTL, cytotoxic T lymphocyte; FasL, Fas ligand; DMEM, Dulbecco's modified Eagle medium; 3HMT, ${ }^{3} \mathrm{H}-$ methyl-thymidine; $\mathrm{T} / \mathrm{E}$ ratio, the ratio of effector cells to target cells.

\section{References}

[1] DuBois, R.N., Tsujii, M., Bishop, P., Awad, J.A., Makita, K., and Lanahan, A.: Cloning and characterization of a growth factor-inducible cyclooxygenase gene from rat intestinal cells. Am. J. Physiol., 266, G822-G827, 1996.

[2] Eberhart, C.E. and DuBois, R.N.: Eicosanoids and the gastrointestinal tract. Gastroenterology, 109, 285-301, 1995. 
[3] Kujubu, D.A., Fletcher, B.S., Varnum, B.C., Lim, R.W., and Herschman, H.R.: TIS10, a phorbol ester tumor promoterinducible mRNA from Swiss $3 \mathrm{~T} 3$ cell encodes a novel prostaglandin synthase/cyclooxygenase homologue. J. Biol. Chem., 266, 12866-12872, 1991.

[4] Mutoh, H., Hayakawa, H., Sakamoto, H., and Sugano, K.: Homobox. protein $\mathrm{CDX} 2$ reduces Cox-2 transcription by inactivating the DNA-binding capacity of nuclear factorkappaB. J. Gastroenterol., 42, 719-729, 2007.

[5] Eberhart, C.E., Coffey, R.J., Radhika, A., Giardiello, F.M., Ferrenbach, S., and DuBois, R.N.: Up-regulation of cyclooxygenase 2 gene expression in human colo-rectal adenomas and adenocarcinomas. Gastroenterology, 107, 1183-1188, 1994.

[6] Elder, D.J.E., Baker, J.A., Banu, N.A.E., Moorghen, M., and Paraskeva, C.: Human colorectal adenomas demonstrate a size-dependent increase in epithelial cyclooxygenase- 2 expression. J. Pathol., 198, 428-434, 2002.

[7] Sheehan, K.M., Sheahan, K., O'Donoghue, D.P., MacSweeney, F., Conroy, R.M., Fitzgerald, D.J., and Murray, F.E.: The relationship between cyclooxygenase-2 expression and colorectal cancer. JAMA, 282, 1254-1257, 1999.

[8] Sinicrope, F.A., Half, E., Morris, J.S., Lynch, P.M., Morrow, J.D., Levin, B., Hawk, E.T., Cohen, D.S., Ayers, G.D., Stephens, L.C., and Familial Adenomatous Polyposis Study Group: Cell proliferation and apoptotic indices predict adenoma regression in a placebo-controlled trial of celecoxib in familial adenomatous polyposis patients. Cancer Epidemiol. Biomarkers Prev., 13, 920-927, 2004.

[9] Steinbach, G., Lynch, P.M., Phillips, R.K., Wallace, M.H., Hawk, E., Gordon, G.B., Wakabayashi, N., Saunders, B., Shen, Y., Fujimura, T., Su, L.K., and Levin, B.: The effect of celecoxib, a cyclooxygenase-2 inhibitor, in familiar adenomatous polyposis. N. Engl. J. Med., 342, 1946-1952, 2000.

[10] Oshima, M., Dinchuk, J.E., Kargman, S.L., Oshima, H., Hancock, B., Kwong, E., Trzaskos, J.M., Evans, J.F., and Taketo, M.M.: Suppression of intestinal polyposis in Apc delta 716 knockout mice by inhibition of cyclooxygenase 2(COX2). Cell, 87, 803-809, 1996.

[11] Kawamori, T., Rao, C.V., Seibert, K., and Reddy, B.S.: Chemopreventive activity of celecoxib, a specific cyclooxygenase-2 inhibitor, against colon carcinogenesis. Cancer Res., 58, 409-412, 1998.

[12] Jacoby, R.F., Seibert, K., Cole, C.E., Kelloff, G., and Lubet, R.A.: The cyclooxygenase- 2 inhibitor celecoxib is a potent preventive and therapeutic agent in the min mouse model of adenomatous polyposis. Cancer Res., 60, 5040-5044, 2000.

[13] Oshima, M., Murai, N., Kargman, S., Arguello, M., Luk, P., Kwong, E., Taketo, M.M., and Evans, J.F.: Chemoprevention of intestinal polyposis in the Apcdelta716 mouse by rofecoxib, a specific cyclooxygenase-2 inhibitor. Cancer Res., 61, 1733-1740, 2001.

[14] Tomozawa, S., Nagawa, H., Tsuno, N., Hatano, K., Osada, T., Kitayama, J., Sunami, E., Nita, M.E., Ishihara, S., Yano, H., Tsuruo, T., Shibata, Y., and Muto, T.: Inhibition of haematogenous metastasis of colon cancer in mice by a selective COX-2 inhibitor, JTE-522. Br. J. Cancer, 81,
1274-1279, 1999.

[15] Li, M., Wu, X., and Xu, X.C.: Induction of apoptosis in colon cancer cells by cyclooxygenase-2 inhibitor NS398 through a cytochrome c-dependent pathway. Clin. Cancer Res., 7, 1010-1016, 2001.

[16] Tsujii, M., Kawano, S., Tsuji, S., Sawaoka, H., Hori, M., and DuBois, R.N.: Cyclooxygenase regulates angiogenesis induced by colon cancer cells. Cell, 93, 705-716, 1998.

[17] Masferrer, J.L., Leahy, K.M., Koki, A.T., Zweifel, B.S., Settle, S.L., Woerner, B.M., Edwards, D.A., Flickinger, A.G., Moore, R.J., and Seibert, K.: Antiangiogenic and antitumor activities of cyclooxygenase-2 inhibitors. Cancer Res., 60, 1306-1311, 2000.

[18] Holash, J., Maisonpierre, P.C., Compton, D., Boland, P., Alexander, C.R., Zagzag, D., Yancopoulos, G.D., and Wiegand, S.J.: Vessel cooption, regression, and growth in tumors mediated by angiopoietins and VEGF. Science, 284, 1994-1998, 1999.

[19] Tsujii, M., Kawano, S., and DuBois, R.N.: Cyclooxygenase-2 expression in human colon cancer cells increases metastatic potential. Proc. Natl. Acad. Sci. U.S.A., 94, 3336-3340, 1997.

[20] Ropponen, K.M., Eskelinen, M.J., Lipponen, P.K., Alhava, E., and Kosma, V.M.: Prognostic value of tumour-infiltrating lymphocytes (TILs) in colorectal cancer. J. Pathol., 182, 318-324, 1997.

[21] Seki, N., Brooks, A.D., Carter, C.R., Back, T.C., Parsoneault, E.M., Smyth, M.J., Wiltrout, R.H., and Sayers, T.J.: Tumorspecific CTL kill murine renal cancer cells using both perforin and Fas ligand-mediated lysis in vitro, but cause tumor regression in vivo in the absence of perforin. $J$. Immunol., 168, 3484-3492, 2002.

[22] Nakayama, M., Kayagaki, N., Yamaguchi, N., Okumura, K., and Yagita, H.: Involvement of TWEAK in interferon gamma-stimulated monocyte cytotoxicity. J. Exp. Med., 192, 1373-1380, 2000.

[23] Farinas, M.C., Rodriguez-Valverde, V., Zarrabeitia, M.T., Parra-Blanco, J.A., and Sanz-Ortiz, J.: Contribution of monocytes to the decreased lymphoproliferative response to phytohemagglutinin in patients with lung cancer. Cancer, $\mathbf{6 8}$, 1279-1284, 1991.

[24] Yoshino, I., Yano, T., Yoshikai, Y., Murata, M., Sugimachi, K., Kimura, G., and Nomoto, K.: Oligoclonal T lymphocytes infiltrating human lung cancer tissues. Int. J. Cancer, 47, 654-658, 1991.

[25] Lang, S., Lauffer, L., Clausen, C., Lohr, I., Schmitt, B., Holzel, D., Wollenberg, B., Gires, O., Kastenbauer, E., and Zeidler, R.: Impaired monocyte function in cancer patients: Restoration with a cyclooxygenase-2 inhibitor. FASEB J., 17, 286-288, 2003.

[26] Brunda, M.J., Herberman, R.B., and Holden, H.T.: Inhibition of murine natural killer cell activity by prostaglandins. $J$. Immunol., 124, 2682-2687, 1980.

[27] Kubota, Y., Sunouchi, K., Ono, M., Sawada, T., and Muto, T.: Local immunity and metastasis of colorectal carcinoma. Dis. Colon Rectum, 35, 645-650, 1992.

[28] Goodwin, J.S. and Ceuppens, J.: Regulation of the immune response by prostaglandins. J. Clin. Immunol., 3, 295-315, 
1983.

[29] O'Connell, J., O'Sullivan, G.C., Collins, J.K., and Shanahan, F.: The Fas counterattack: Fas-mediated $\mathrm{T}$ cell killing by colon cancer cells expressing Fas ligand. J. Exp. Med., 184, 1075-1082, 1996.

[30] Villunger, A., Egle, A., Marschitz, I., Kos, M., Bock, G., Ludwig, H., Geley, S., Kofler, R., and Greil, R.: Constitutive expression of Fas (Apo-1/CD95) ligand on multiple myeloma cells: a potential mechanism of tumor-induced suppression of immune surveillance. Blood, 90, 12-20, 1997.

[31] Gastman, B.R., Atarshi, Y., Reichert, T.E., Saito, T., Balkir, L., Rabinowich, H., and Whiteside, T.L.: Fas ligand is expressed on human squamous cell carcinomas of the head and neck, and it promotes apoptosis of $\mathrm{T}$ lymphocytes. Cancer Res., 59, 5356-5364, 1999.

[32] Bennett, M.W., O'Connell, J., O'Sullivan, G.C., Brady, C., Roche, D., Collins, J.K., and Shanahan, F.: The Fas counterattack in vivo: apoptotic depletion of tumor-infiltrating lymphocytes associated with Fas ligand expression by human esophageal carcinoma. J. Immuno., 160, 5669-5675, 1998.
[33] Ryan, A.E., Shanahan, F., O'Connell, J., and Houston, A.M.: Addressing the "Fas counterattack" controversy: blocking fas ligand expression suppresses tumor immune evasion of colon cancer in vivo. Cancer Res., 65, 9817-9823, 2005.

[34] Jones, M.K., Wang, H., Peskar, B.M., Levin, E., Itani, R.M., Sarfeh, I.J., and Tarnawski, A.S.: Inhibition of angiogenesis by non steroidal anti-inflammatory drugs:insight into mechanisms and implications for cancer growth and ulcer healing. Nat. Med., 5, 1418-1423, 1999.

[35] Uefuji, K., Ichikura, T., Shinomiya, N., and Mochizuki, H.: Induction of apoptosis JTE-522, a specific cyclooxygenase-2 inhibitor, in human gastric cancer cell lines. Anticancer Res., 20, 4279-4284, 2000.

[36] Andreola, G., Rivoltini, L., Castelli, C., Huber, V., Perego, P., Deho, P., Squarcina, P., Accornero, P., Lozupone, F., Lugini, L., Stringaro, A., Molinari, A., Arancia, G., Gentile, M., Parmiani, G., and Fais, S.: Induction of lymphocyte apoptosis by tumor cell secretion of FasL-bearing microvesicles. $J$. Exp. Med., 195, 1303-1316, 2002. 